\title{
The clinical setting and the Doctor-Patient (therapeutic) relationship
}

\author{
Marc Gérald CHOUKROUN
}

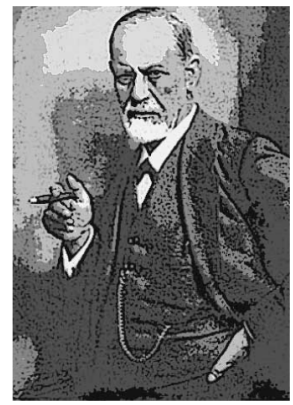

\section{ABSTRACT}

It is commonly accepted that a good practicioner-patient relationship favours good patient co-operation with treatments. However, medical literature and our own research have led us to a more pertinent approach. The body and the mind cannot be dissociated in humans and numerous observations show that therapeutic results are favoured by the human relationship. (Given similar techniques, biological answers differ). Now concerning the environment, the question is:

"How can the clinical framework integrate this research?"

\section{KEYWORDS}

Doctor-Patient relationship

Psychology

Communication

Architecture. 


\section{1 - THE PRACTIONER-PATIENT RELATIONSHIP}

\section{1 - 1 - Review of epistemology}

Medicine progresses in a mechanistic dynamic, apparently ignoring the fact that the human being is a whole, composed of a body and a mind. The distinction of body and mind is, itself, suspicious ideologically, for the most objective reality should not dissociate them.

This issue finds its roots in the history of occidental thought with the birth of monotheism ( $\sin$ on the flesh). However, we will be brief and begin with the Enlightenment.

Kant, Hegel were apostles of phenomenology. Hume, Hobbes were the philosolophers of sensuality. The Enlightenment in any case preferred to dissociate the exterior world (Umwelt) and the interior world (Innerwelt), with the learned project of leaving philosophers to explore the interior world (phenomenology of the mind) and progressively dedicating themselves to the study of observable facts, capable of establishing a consensus (Descartes in the $17^{\text {th }}$ century already named it "rex extensa": the extended or exterior world). Finally rid of religious beliefs, doctors, alchemists and astronomers could develop an encyclopaedic knowledge (Diderot, d'Alembert). the high point was attained with Auguste Comte in the $19^{\text {th }}$ century, who exhorted sages to embrace "efficacious" (efficient) knowledge.

Towards the end of the $19^{\text {th }}$ century, psychologists and psychoanalysts restored a balance between body and mind, and showed that numerous diseases were rooted in psychological disorders.
This is why we should keep in mind that our treatments must integrate both dimensions to be efficacious.

The patient's environment enters into this logic and must be conceived not only to please the nursing staff, but also to please the patient, so together they feel they can exercise their art under the best conditions, on the one hand, and confide their bodies, on the other.

\section{1 - 2 - The nature of the cure}

Numerous authors thus affirm that the issue of treatment depends in part, sometimes wholly, on the doctorpatient (therapeutic) relationship or simply on the personality of the patient.

Thus, Bernie Siegel ${ }^{3}$ states that if his patient tells him at the first consultation that he wants to live till 90 year old, he knows that the chances are that a cure for his cancer is possible.

Inversely, when the patients despairs or is in conflict with the doctor, the issue of treatment becomes uncertain.

Studies of medical psychology and stress hormones ${ }^{6}$ show essentially that certain treatments failures are related to diminished immunity.

The placebo effect ${ }^{4}$ measured systematically in double blind protocols by pharmaceutical laboratories demonstrates every day treatment depends on the human relationship. What is the mysterious effect of a placebo? The answer is twofold; 
- according to Freud is it a question of a relationship of transfer ${ }^{5}$.

- according to the laboratory research, it seems to be related to the marketing pill appearance ${ }^{7}$.

Transfer is a strictly human situation, which activates the fundaments of the human being's relations of identity with is most precious loved one: his mother. The patient's second most adored object is his body, with which he built up as an intimate relation of live as with his mother. Thus, by conditioned reflex, as soon as the patient has an attack on his body's integrity, he actively seeks the references elaborated by his body and his ego (self. Id). Despite everything, the practitioner finds himself the object of an imaginary target of an associative relationship: body, mother, doctor. If this relationship is fulfilled, the patients is reassured concerning his corporal and affective dangers and rouses himself psychologically and biologically to be cured "out of love for the doctor", just as a pupil can learn out of love for this teacher. This is the positive transfer.

The pill presentation effect is corelated with social factors, that contribute to set his own conviction: the medical power of the pill. Nevertehless, P. Lemoine ${ }^{7}$ insists on the fact that when informed about the false nature of the medical prescription, the practicioner increases his effecct. The trust of placebo has to be imagined by both actors: it is so called transfer.

Finally, let's not forget that transfer functions both ways: the patient can also suggests to the doctor that he is going to get well or not and thus condition the effect of the cure.

The efficacy of a given treatment may be radically different as a function of the transfer relationship. We described this relationship, as dependant on the attitude of the practitioner ${ }^{5}$, but it is also interesting to understand that transfer functions in all nursing settings: personnel, decoration, and ambience.

\section{2 - THE BASIS OR THE PRACTICIONER-PATIENT RELATIONSHIP IN ORTHODONTICS}

In our work, the "Carrying out of treatment" 4 , we proposed six dimensions to assist health professionals in defining the doctor-patient (therapeutic) relationship.

We will try to apply these concepts. The six dimensions are: biotechnology, information, psychoeducational methods, the human relationship, psychological and social factors, and supervision.

Since the environment is fundamental, we will show how to apply educational, relational and supervisory factors to it. Biotechnology will be the object of an entire book, since it involves all technology and its ergonomics. It will not be discussed here.

\section{2 - 1 - The psycho- educational relationship}

When the practitioner or his assistant is asked to explain a method of functional education, it is well understood that reference to an educational method is necessary. Actually, as soon 
as on must explain something to a patient, it is an educational action. We will include in this term a certain number of verbal acts as being educational. For example, if you explain an anomaly, if a treatment schedule is presented for commentary to the patient, it is an educational act. If post-operative advice is give, if the operation is explained, here again it is an educational act and explanation of administrative details is again an educational act. It seems necessary to envisage an adapted working technique.

Thus today, we can any longer imagine a nursing setting without considering its educational organisation.

\section{2 - 2 - The human relationship}

Old DFO doctors' offices were essentially designed by the practitioner, for the practitioner. It required the help of certain marketing specialists to finally realise that an office is also the patient's environment. Do you really need commercial effects to enhance the sterilisation room? In today's modern society, is it really necessary to reassure the patient that we respect the rule of hygiene?

Is it truly a commercial act to offer coffee to a patient who must wait a long time in the waiting room? If our idea of a human relationship is to propose a relationship "centered around the patient" according to Karl Roger's theory ${ }^{8}$, then the architectural envi-

\section{3 - EXAMINATION OF THE LITTERATUR}

Few publications treat the situation of the patient in the clinical environment in an empathetic way. The deco- ronment should take this principle into consideration.

\section{2 - 3 - The supervision}

We have developed an original concept, inspired by studies of the medical psychology of support ${ }^{4,6}$. Observations show that a patient supported by his friends and family in three ways (affective, psychological an material) develops better biological and psychological defences to help his body recover.

Here again, it is surprising to note the necessity of developing protocol studies to underline the need for human support, while the medical team can provide it more efficiently and professionally.

Material support is technical assistance, affective support is transfer, and psychological, support consists of encouraging the patient and in not reprimanding him. This effect is multiplied by the number of caretakers.

\section{2 - 4 - Conclusion}

The architectural conception of the nursing setting must, therefore, embody education method, transfer relationships and supervision.

Too often, the practitioner organised this setting to suit his tastes instead of asking the essential question: if I were a patient coming into my office, what would I need, what would I like to see, how would I like to be greeted?

rators and builders, like certain practitioners, are intimately convinced that if the work is well done, the client will 
be satisfied. Now this situation in our eyes is only half of an environmental strategy. It is thus that one sees architects build magnificent, but unliveable, edifices.

We are therefore going to revisit certain reflections, which will set the reader on the track of a novel concept.

\section{3 - 1 - Alain Amzalag ${ }^{1}$ : chapter 6 "first steps in an office"}

"That makes one think at the reception that one is received in a Moroccan Hotel. The employees, the servers received no particular training in management and were not trained at the Hotel School of Lausanne. Nevertheless, they are able to make the visitor feel like an invited guest and not a mere client.

"Unfortunately, at the doctor's, this sense of welcome is often absent and, on the contrary, one feels a certain coldness. Our education pushes us to distance ourselves in order to protect our authority, our know-how. But coldness does not invite communication, a human relationship".

"- It is not obvious luxury that will condition the patient's well being. On the contrary, ostentatious luxury can be embarrassing and hinder communication.

- For the environment to be appeasing it should favour clear, rather than vivid, too aggressive colours".

"One should not hesitate to sit down in one's own waiting room, a place where one could sit down for a drink. We all know those waiting rooms with a row of rustic chairs and a bar, several inches off the floor, to protect the chair backs from damaging the wall: it's sordid."

"When i started out, i didn't dare offer coffee to my patients because i feared they would interpret it as a commercial gesture. That was an error: it is foremost a human gesture."

"One must not forget that the time spent in the waiting room will change a person's state of mind. The more comfortable those minutes, the more the patient is relaxed."

\section{3 - 2 - Charles-Daniel ARreto et al. ${ }^{2}$ : chapter 3 "Non verbal communication by the environment"}

"The environment can be defined as that which surrounds the patient the minute he enters the door of the office. This environment consists of human constituents (receptionist, assistant...) and technical constituents (material, decoration, environmental sounds...). The office as a whole, communicates emotions through its ambience. One can use the office as a means of communication by sending sounds, shapes, messages, which can agreeably influence the patient's emotions..."

"the office environment gives the patient an idea of the practitioner's character through his tastes..."

"A personal touch in the office makes the patient's feel closer to his practitioner..."

"thus the smell of eugenol elicits a reaction, but may be loaded with memories. If the patient associates a painful experience with this (synthetic) 
odour, he will associated pain with the odour..."

"The objective for the practitioner is to organise the environment according to the patient's perception: what he sees, hears and smells, watching for the first visual impressions of the office, the noises and perceptible odours from the operating.

Arreto (et al.) suggest analysing the various styles usually encountered.

- The medical style: this is waiting room with white walls, uniform furniture, and a neutral colour. There is little decoration, mainly with posters of information about odontology.

- The relaxed style: as opposed to the medial style, there are no posters and the furniture is comfortable, the lighting dim, and the colours warm.

- The convivial style: based on simplicity, is a compromise between a relaxation area and a room where one can amuse oneself and consult information about odontology.

- No particular ambience: a waiting room devoid of style and with no harmony due to negligence of the presence of heterogeneous furniture and materials.

Arreto gives various pieces of advice, which bring nothing that the Cartesian mind cannot discover on its own. However, as concerns lighting, certain remarks are original:

"Natural light creates a very agreeable setting. Its only inconvenience is its instability, since at certain times of day, notably at dawn and sundown, it is of mediocre quality..."

"A room with too little light can give a feeling of insecurity..."
"Inversely, a room with too much lighting makes one introverted, which can lead the patient to close up..."

"A good contrast is obtained by alternating the intensities of the decorative lighting illuminating valuable objects..."

Finally, some observations are interesting to keep in mind:

"Plants are in general appreciated...a contrast with the medical style, favouring appeasement.

Paintings dress up a room, but themes evoking the world of dentistry should be avoided.

As to furnishings, those allowing the patient to sit down should be favoured over individual seats around a coffee table. A sofa is justified for patients who are closely related (motherchild)...Armrests are also advised.the furniture should be made wood or plastic, which are more agreeable to touch than metal..."

"Respecting certain thermo-hygrometric parameters adds to the patient's comfort:

- the temperature of the waiting room should be adapted to the season, to the room and the number of windows and the greater or lesser activity of the waiting room;

- positioning chairs close to a window is not recommended;

- humidification of air dried by heating is indispensable in winter;

- inversely, drying the air to favour sweating, necessary for good thermal balance, is indispensable in summer;

- half opening of shutters in summer is possible, to reduce direct sunlight and avoid over-heating." 


\section{4 - I, THE PATIENT, COME INTO AN OR THODONTIST'S OFFICE}

\section{4 - 1 - The reception}

As I open the door, I would like to be surprised by a lovely light. I would like to see signs of welcome, like a sign saying "Welcome to the office of $X^{\prime \prime}$ or perhaps a photo of child saying hello or simply a bouquet of flowers. I would like a pretty gay colour to accompany this ambience, like a straw yellow or sky blue or apple green.

I would like to have a person come up to me with a big smile and say:

"Hello, we were waiting for you, come with me, my name's Sophie. How did you get our address?" Etc.

Before reaching the waiting room, I go by doors and ask myself what mystery hides behind them. This unsettles me and, if I wonder if I need to go to the toilet, how I will find it and where is the doctor who will see me?

For this reason, there should be a sign on each door saying "Doctor $X$ ", "sterilisation room," laboratory", "toilets," and "waiting room." I can thus already orient myself and that reassures me.

Along the way, bare walls disturb me and give the impression that their only concern is teeth with a certain indifference towards me. Painting or lively things would suit me better: a picture taken on a trip by the doctor, a photo of staff showing that they are happy to work together or they get along well, a photo of a happy patient, or a painting indicating that the doctor has a good taste and is cultivated.

After a few seconds, i feel better in this office and feel I have made a good choice. Horrible the office where I follow arrows indicating the waiting room and have an impression of bothering them.

Horrible the office with white walls covered with uninteresting posters where I feel anonymous.

\section{4 - 2 - The waiting room}

The assistant opens the door. I notice at first sight, there is someone else.

Often this person doesn't even glance at me or gives me a judgmental look. I know that if I sit next the person I may feel a little in competition with him. I hate that. What would I like? I would like the assistant to introduce me to the person, I will thus be sure that we will smile to each other and the relationship will be different.

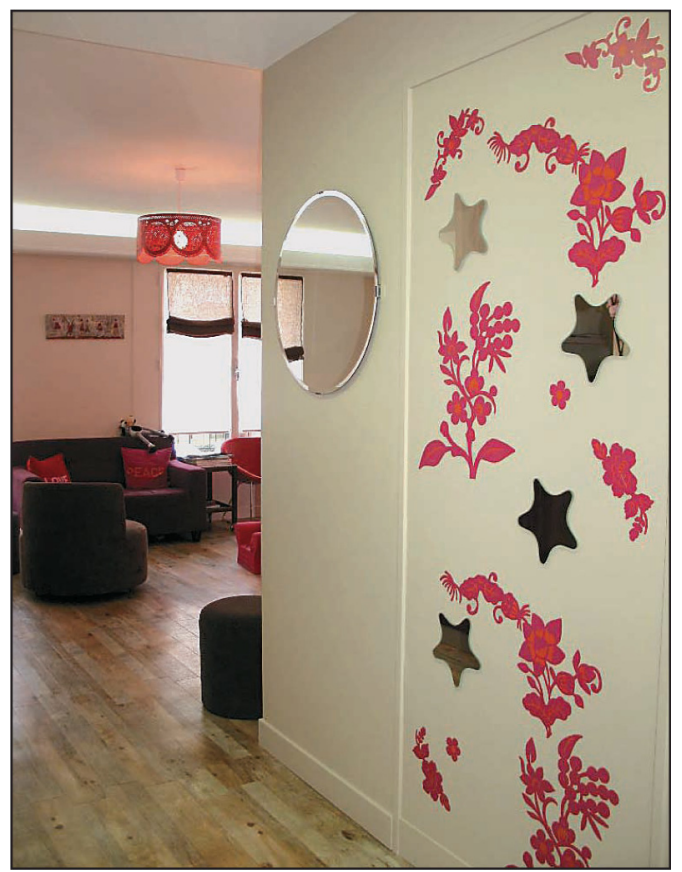

Cabinet des Dr Mer et Tavernier 
"Mr. Smith, may I introduce Mr. Jones, who works in television, a very interesting person...?"

Then my waiting time is transformed into a meeting time.

Chairs aligned along the wall remind me of a train station, a social security waiting room, all I have to do is to take a ticket for my turn. No, that isolates me. What I should like is that the room be like a living room, conducive to chatting or reading, with chairs that relax my body and make me feel confident. I would like soft lighting, light allowing me to read and discreet lighting (lamps or wall fixatures) suggesting intimacy.

I don't like waiting rooms with disparate objects, as if the doctor wanted to get rid of some furniture and economise.

I don't want the decor to be too valuable, for my children accompany me and I must constantly watch out that they don't damage the precious objects. On the contrary, I would like the doctor to have objects that interest my children, with which they can play, like building blocks or drawing materials or even a drawing contest, which would encourage them to concentrate...

A small desk might also be welcome so they can begin their homework since they have their school bags.

I like relaxing waiting room colours, which contrast with the entrance way, so as to be relaxed upon entering the treatment room. A frank green, a grey-bleu or good materials that give substance to a room: wood, tile, metal...

I would like to hear soft, soothing music.
If there is any important news, I prefer to be informed and use my waiting time to be updated, for I am afraid the doctor will talk about things that concern me, but that he won't have time to warm me about other things, which are too repetitive for him.

Therefore, there should be magazines on the waiting room table and informative leaflets placed separately elsewhere. I remember there was a leaflet on a table in a hotel lobby that gave all the events occurring in the area, so in a few minutes I knew about the most important.

In an orthodontist's office, I would like to know what is going to happen, what are my risks. Is there something that might change the course of my life, or that of my children? What is going to happen today? Are they going to immediately put in an apparatus or give me injections?

How can I reassure my son, who is expecting to be aggressed?

The assistant could tell me, but I don't dare disturb her.

I wish she would inform me a little, that would rid me of my questions and my anxiety.

About the financial aspects, will they ask for extravagant sums, will I have time enough to agree? A simple notice could satisfy me.

Ah! Here is the doctor! He doesn't even look at me, for it is the turn of person next to me. Am I so transparent?

This time it's my turn. I wish he would smile, which is the best way to make me fell confident. 


\section{4 - 3 - Treatment room}

He opens the door of the treatment room, what a mess! There are objects and instruments everywhere. How does he find what he needs? He gives the impression of not being organised.

I would like an office where things are in drawers to make it nearer. There is a computer in evidence; it is good for me! He is modern.

The room is cold. I already can feel the hardness of the metal instruments in my mouth.

I wish the walls were painted in a light colour, so as to be professional and that the furniture was watched. A pretty decoration is a guarantee for me that he is someone competent. I could be glad to discover personal objects, which would give an idea of his personality so that he doesn't remain a mystery, and so that I meet someone interesting.

I would like to be greeted by everyone who takes care of me, the same as in a plane company, where the crew welcomes you at your first step.

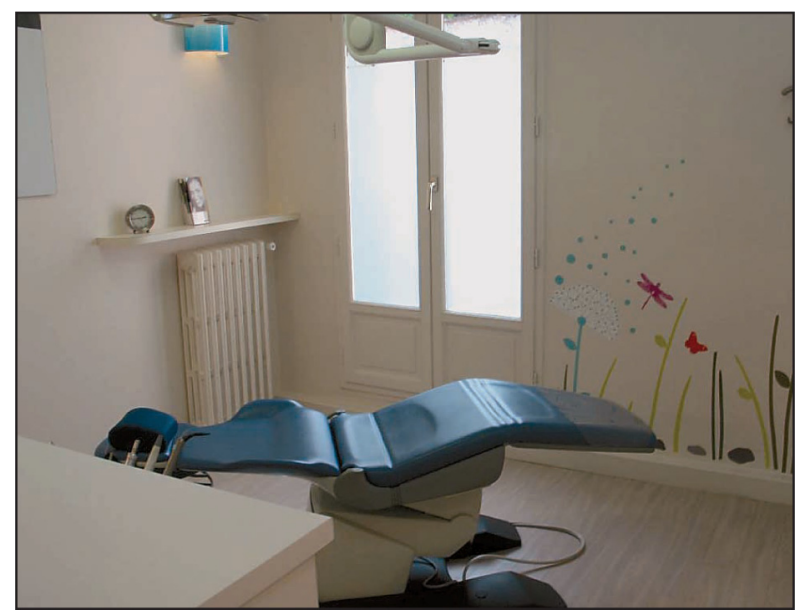

Cabinet des Dr Mer et Tavernier
That would give the feeling of a solid team, who will assure my security. I could then turn over my children to these people without fear.

He has been talking for ten minutes, explaining complex things I don't know about. Why doesn't he ask me what concerns me, what i am afraid of or, better, what I want to know?

His assistant stands behind him like a figurehead. She serves no purpose. Maybe she knows nothing about this profession?

If she spoke to me, I would feel part and taken well in hand.

I am happy to see that they have new, clean lab coats, each of a different colour.

That way I know who is the doctor, who the assistant and who is the secretary...

Actually, what I would like is that the doctor tell me rapidly about my son's problem, if it is serious, how it is treated, how long it will take. Even if he uses technical terms, which proves he is a scientist, and above all, that he is interested in me asking questions.

\section{4 - 4 - Psycho-educative office}

Ideally, the assistant should take me to another room to allow the doctor to continue his consultations and, in a simply and convivial manner, answer my questions and help me with necessary formalities.

In this room, there should be a screen for projecting simple explanatory pictures and slides, which summarise the essentials. Perhaps after explaining certain things, she could 


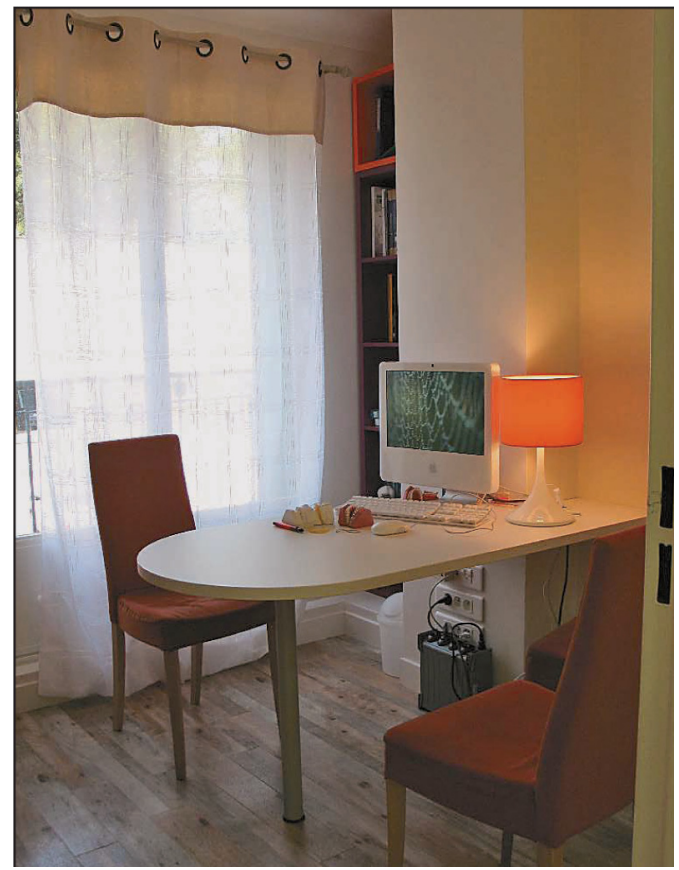

Cabinet des Dr Mer et Tavernier

give me a leaflet summarising these things.

If the session is clear, I gain confidence and leave reassured, certain that I have made the right choice.

\section{4 - 5 - The secretary}

Before leaving, I wish the assistant would accompany me to the secretary, who will then tell me kindly about the necessary formalities. I hate secretaries who spew out the necessary information and make you ill at ease when you haven't understood and ask them to repeat.

The secretary should be brief and give me documents that explain everything. She can also place posters behind her desk to alert me about certain requirements ("and particularly not forget to send you biannual request to the health insurance").

The secretary's area should be able to see the appointment book to make an appoint ment or at least have a board with working hours indicated on a calendar.

Then, if I must do something, I would like the secretary to write it down with the address and telephone number.

\section{5 - CONCLUSION}

Rather than saturating the reader with information and obligations and increasing his responsibility, we have tried, through lively descriptions, to show that notions of education and transfer, essential to the workings of a treatment, be integrated by the medical team, the dialogue and the architectural structure. Beforehand, it was necessary lay down the theoretical principles.

\section{REFERENCES}

1. Amzalag A. Codes de la relation dentiste-patient. Issy-les-Moulineaux: Masson, 2007;124.

2. Arreto C, Brunet-Canone A, Fioretti F. Consulter en odontologie. Pays Bas: Ed CdP, 2006;127.

3. Bernie S. S. L'amour, la médecine et les miracles. Paris: J'ai Lu éd., 2001;305.

4. Choukroun MG. La mise en acte du traitement. Paris: SID, 2004;242. 
5. Choukroun MG. Au cœur de la relation thérapeutique. Paris: Glyphe éd., 2007;240.

6. Dantzer R, Bruchon-Schweitzer MM. Introduction à la psychologie de la santé. Paris: P.U.F. éd., 2000;210.

7. Lemoine P. Le mystère du placebo. Paris: Odile Jacob éd., 1996;236.

8. Rogers CR. Le développement de la personne. Paris: Dunod, 2001;270. 